\title{
Circulating Endothelial Cells and Endothelial Progenitor Cells in Obstructive Sleep Apnea
}

\author{
Kevin Martin, \\ Vascular Research Laboratory, Providence Veterans Affairs Medical Center, 830 Chalkstone \\ Avenue, Providence, RI 02908, USA \\ Pulmonary/Critical Care/Sleep Medicine, Warren Alpert Medical School, Brown University, \\ Providence, RI 02912, USA \\ Michael Stanchina, \\ The Rhode Island Hospital, Providence, RI 02903, USA \\ Pulmonary/Critical Care/Sleep Medicine, Warren Alpert Medical School, Brown University, \\ Providence, RI 02912, USA \\ Nicola Kouttab, \\ Roger Williams Medical Center, Providence, RI 02908, USA \\ Elizabeth O. Harrington, and \\ Vascular Research Laboratory, Providence Veterans Affairs Medical Center, 830 Chalkstone \\ Avenue, Providence, RI 02908, USA \\ Pulmonary/Critical Care/Sleep Medicine, Warren Alpert Medical School, Brown University, \\ Providence, RI 02912, USA

\section{Sharon Rounds} \\ Vascular Research Laboratory, Providence Veterans Affairs Medical Center, 830 Chalkstone \\ Avenue, Providence, RI 02908, USA \\ Pulmonary/Critical Care/Sleep Medicine, Warren Alpert Medical School, Brown University, \\ Providence, RI 02912, USA \\ Sharon Rounds: Sharon_Rounds@brown.edu
}

\section{Abstract}

Increased circulating endothelial cells (CECs) have been observed in patients with vascular injury associated with acute myocardial infarction, pulmonary hypertension, and congestive heart failure. Decreased circulating endothelial progenitor cells (EPCs) have been observed in patients with risk factors for cardiovascular disease. Obstructive sleep apnea (OSA) is associated with increased risk of cardiovascular disease and endothelial dysfunction. Subjects were recruited from patients referred for overnight polysomnograms; 17 subjects had OSA and 10 control subjects did not have OSA. All subjects lacked vascular disease and risk factors for vascular disease. Peripheral blood was obtained from fasting subjects in the morning, following sleep studies. CECs and EPCs were quantified using magnetic bead separation with UV epifluorescence microscopy and flow

(C) Springer Science+Business Media, LLC 2008

Correspondence to: Sharon Rounds, Sharon_Rounds@brown.edu.

K. Martin and M. Stanchina contributed equally to this work.

Work was performed at Vascular Research Laboratory, Providence VA Medical Center, Providence, Rhode Island.

These results were presented at the 2005 American Thoracic Society international meeting and were published in abstract form in the Proceedings of the American Thoracic Society. 
cytometry immunophenotyping, respectively. Cell counts and demographic variables were compared using unpaired $t$ tests. Regression analysis was performed comparing cell counts with the apnea-hypopnea index (AHI) and nadir $\mathrm{SaO}_{2}$. Subjects with OSA and controls did not differ significantly in terms of age and body mass index. Subjects with OSA had higher AHI, lower nadir $\mathrm{SaO}_{2}$, and greater sleepiness (Epworth Sleepiness Scale scores). There were no significant differences in CEC ( $7.0 \pm 1.5$ vs. $4.9 \pm 0.9, p>0.05)$ or EPC $(1077 \pm 318$ vs. $853 \pm 176, p>0.05)$ between controls and OSA cases, respectively. In this small study, we found no differences in CECs or circulating EPCs between patients with OSA and controls. OSA may not be associated with these markers of vascular endothelial cell injury in patients with no concomitant vascular disease.

\section{Keywords}

Circulating endothelial cells; Progenitor endothelial cells; Obstructive sleep apnea

\section{Introduction}

There is evidence of a clear association between obstructive sleep apnea (OSA) and cardiovascular diseases, including hypertension [1], congestive heart failure [2], coronary artery disease, and stroke [3]. Endothelial cell injury or dysfunction is important in the pathogenesis of cardiovascular disease [4]. There is growing evidence that patients with obstructive sleep apnea (OSA) have evidence of endothelial dysfunction, as assessed by functional measures such as endothelial-dependent vasodilation [5, 6]. Circulating endothelial cells (CECs) have been reported to be increased in a variety of conditions in which vascular injury might be expected, such as sickle cell anemia with crisis [7], acute coronary syndrome [8], congestive heart failure [9], both primary and secondary pulmonary hypertension [10], and systemic sclerosis [11]. It is possible that detached circulating endothelial cells are a marker for vascular endothelial cell damage and thus might be elevated in patients with OSA.

There is growing evidence that postnatal neovascularization involves circulating endothelial progenitor cells (EPCs) derived from bone marrow [12]. Decreased levels of circulating EPCs have been reported to be predictive of future cardiovascular events in patients with stable coronary artery disease and acute coronary syndromes [13] and in patients with angiographic evidence of coronary artery disease [14]. In contrast, increased circulating EPCs were associated with survival in patients with acute lung injury [15]. Thus, circulating EPCs may be predictive of favorable outcome from vascular injury.

In this study, we prospectively assessed whether CECs and circulating EPCs are markers of the cellular response to vascular injury in patients newly diagnosed with OSA but without concomitant vascular disease. We hypothesized that increased numbers of CECs and decreased numbers of EPCs would be observed in this cohort of untreated OSA patients.

\section{Methods}

\section{Study Participants}

This study was approved by the Institutional Review Boards of The Rhode Island Hospital and the Providence VA Medical Center. Subjects were recruited for this study from patients referred for overnight polysomnograms at The Rhode Island Hospital. After patients had been diagnosed with OSA (apnea-hypopnea index [AHI] of $>10$ events/h), they were approached about participation in the study by either a study coordinator or principal investigator. Age- and weight-matched controls with AHI $<5$ events/h were also recruited 
from this population undergoing clinical polysomnography. Exclusion criteria included known coronary artery disease, congestive heart failure, cor pulmonale, systemic or pulmonary hypertension, sickle cell disease, diabetes mellitus, systemic hypertension, hypercholesterolemia, current tobacco use, collagen vascular disease, or pregnancy.

\section{Polysomnography}

Consecutive subjects were evaluated in the Sleep Disorders Center at The Rhode Island Hospital and underwent full in-laboratory overnight polysomnography prior to enrollment. Subjects were instrumented in the hour before the study. Sleep was recorded and scored according to standard methods [16], measuring electroencephalogram, limb movements, extraocular movements, chin electromyogram (EMG), airflow at the mouth and nares by thermister, nasal pressure (Protech, Woodinville, WA), chest and abdominal wall movement (piezo belts, New Life Technologies, Midlothian, VA), anterior tibialis EMG, electrocardiogram, and arterial oxygen saturation $\left(\mathrm{SaO}_{2}\right.$, Sensormedics, Yorba Linda, CA). The signals were recorded on computer (Dell Optiplex GXI recording system, VA) using Sensormedics software (Sensormedics, Yorba Linda, CA). Obstructive breathing events (apneas and hypopneas) were defined and scored according to standard research criteria [17]. Hypoxemia was quantified by the nadir saturation (\%) during obstructed events. Sleep fragmentation was quantified using the number of American Sleep Disorders Association (ASDA)-defined ( $\geq 3 \mathrm{~s}$ ) arousals and awakenings ( $\geq 15 \mathrm{~s}$ ). All studies were reviewed and interpreted by a study-blinded, board-certified, sleep medicine physician.

\section{Venous Blood Sampling}

In the morning after sleep, within 2 weeks of the initial polysomnogram (and prior to any treatment for OSA), a fasting blood sample was obtained by venipuncture of an antecubital vein with a 21 -gauge needle. The first $10 \mathrm{ml}$ of whole blood from each phlebotomy was discarded and not used for cell analysis to avoid contamination of the sample by endothelial cells dislodged by venipuncture. The next $12 \mathrm{ml}$ of blood was collected into heparinized or EDTA-coated tubes for subsequent analysis.

\section{Circulating Endothelial Cells (CECs)}

CECs were isolated using magnetic beads by the method described by Solovey et al. [7]. Magnetic beads precoated with pan mouse IgG (Dynal Biotech/Invitrogen, Carlsbad, CA) were washed in phosphate-buffered saline (PBS) plus $0.1 \%$ bovine serum albumin (BSA). Beads $\left(2 \times 10^{7}\right)$ were incubated with $1 \mu \mathrm{g}$ mouse a-CD146 (Upstate Chemicon, Temecula, CA) in $1 \mathrm{ml}$ PBS plus BSA for $30 \mathrm{~min}$. Whole blood ( $8 \mathrm{ml}$ ) was collected in EDTA tubes, centrifuged, and the buffy coat was washed in PBS plus BSA and $1 \mathrm{mM}$ EDTA and then resuspended with $5 \times 10^{5}$ beads $/ \mathrm{ml}$. Beads were incubated with tilting for $15 \mathrm{~min}$, then separated from the blood mixture with a magnetic concentrator (Dynal Biotech/Invitrogen, Carlsbad, CA) and washed $5 \times$ with PBS plus BSA. The beads were then vigorously micropipetted and resuspended with $1 \mu \mathrm{g} / \mathrm{ml}$ Hoechst. Endothelial cells were manually counted by an observer blinded to patient status using UV epifluorescence microscopy. CECs were identified by cell diameter of 20-50 $\mu \mathrm{m}$, distinguishable nucleus and cytoplasm, and surrounded by a rosette of more than four beads. Data were expressed as cells per milliliter of blood.

\section{Circulating Endothelial Progenitor Cells (EPCs)}

The method described by Del Papa was used [11]. Blood (4 ml) was collected in heparinized tubes and incubated in 200- $\mu$ l aliquots for $15 \mathrm{~min}$ with fluorochrome-conjugated monoclonal antibodies CD45-APC, CD34-PerCP, and CD133-PE (Becton-Dickinson, Franklin Lakes, $\mathrm{NJ})$. Red blood cells were lysed with lysing solution (Becton-Dickinson) and three-color 
flow cytometry analysis was performed with collection of 200,000-600,000 events using a FACS Calibur (Beckton-Dickinson). Isotype controls were used to confirm low nonspecific binding. Gating analysis was performed on all nondebris events with lower side scatter than the lower bound of the monocyte gate. A reproducible population of cells that exhibited a highly positive CD34 signal and a weakly positive CD45 signal (less than that of the Lymphocyte gate but greater than that of the negative control) was identified. Cells in this gate were considered circulating EPCs if they also expressed a highly positive CD 133 signal. All analysis was performed by an observer blinded to patient status. Results were expressed as cells per milliliter of blood.

\section{Statistical Analysis}

All data are presented as mean \pm SEM. Differences between means were tested for significance using an unpaired Student's $t$ test. Differences were considered significant when $p<0.05$. Confidence interval for the difference between two means was determined as at confidence level of $95 \%$.

\section{Results}

Figure 1 is illustrative of a typical experiment purifying circulating endothelial cells from whole blood using immunomagnetic beads bound to a-CD146, an antibody known to purify mature endothelial cells. Figure 2 illustrates flow cytometry immunophenotyping of circulating endothelial progenitor cells. A population of cells with distinct forward-scatter and side-scatter characteristics (RI) (Fig. 2a) was shown to express high levels of CD34, yet low levels of CD45 (Fig. 2c). A subset of these cells (R2) further demonstrated high levels of CD133 (Fig. 2d), yet negative for CD146 (Fig. 2e). These data are characteristic of flow cytometry immunophenotyping of EPC.

Subject characteristics described in Table 1 demonstrate that subjects with OSA did not differ significantly from controls without OSA in terms of age and body mass index. Predictably, subjects with OSA had higher AHI, lower nadir $\mathrm{SaO}_{2}$, and greater sleepiness, as assessed by Epworth Sleepiness Scale scores.

The numbers of CECs and circulating EPCs in subjects with OSA and controls are depicted in Fig. 3. There were no statistically significant differences between the groups with respect to numbers of CECs (95\% confidence interval $[\mathrm{CI}]=1.018-5.062, p=0.18$ ) and circulating EPCs $(95 \% \mathrm{CI}=464.48-911.54, p=0.51)$. Assessment of correlations between numbers of CECs and circulating EPCs and AHI and nadir $\mathrm{SaO}_{2}$ in all subjects yielded no statistically significant correlations.

\section{Discussion}

In this study we observed no statistically significant differences in either circulating endothelial cells or circulating endothelial progenitor cells in the blood of subjects with OSA compared with that of age- and weight-matched controls. This result was surprising in view of the clear association of OSA with cardiovascular disease [18] and evidence of endothelial dysfunction in OSA [5, 6]. There are several possible reasons for our findings. First, the numbers of CECs and circulating EPCs that can be identified from peripheral blood samples are small, even in patients with cardiovascular disease [19]. The number of CECs in control subjects is similar to that reported by others [7-9]. Thus, due to the relatively rare event analysis, the sample sizes in this study may have been too small to detect differences. Our results suggest a trend for decreased CECs and EPCs in OSA. 
We purposely excluded subjects with pre-existing vascular disease (such as sickle cell anemia or scleroderma), a condition known to be associated with altered numbers of CECs or circulating EPCs, and those with risk factors for cardiovascular disease. The reason for these exclusions was that we wished to assess the effect of OSA alone on CECs. Thus, it is possible that changes in CECs and circulating EPCs are present in patients with concomitant OSA and cardiovascular disease. In addition, there may be differential susceptibility to cardiovascular disease in OSA patients depending on predisposing factors such as degree of sleepiness [20] or fat distribution [21].

We obtained blood samples from patients in the morning. It is possible that CECs and circulating EPCs are elevated only during sleep-associated hypoxemia or have some degree of circadian rhythm that is not known. There is previously identified circadian variability in the blood pressure of OSA patients, the so-called "nondipping" [22], and in more specific tests of endothelial integrity such as flow-mediated endothelial relaxation, circadian variation has been identified [23].

These studies were done at the time of diagnosis of OSA. We do not know how long OSA had existed in these subjects. It is possible that there is a threshold duration of OSA that is necessary for changes in CECs and circulating EPCs to be observed.

Finally, we assessed circulating EPCs using flow cytometry alone. It is possible that the assay of endothelial colony-forming units [24] might be more specific and therefore more likely to detect differences between subjects with OSA and controls.

The impact of hypoxia has been described as an important determinant of endothelial injury in OSA patients [25]. The subjects in this study had moderate degrees of desaturation, as assessed by nadir $\mathrm{SaO}_{2}$. If hypoxia is critical to changes in either CECs or circulating EPCs, then it is possible that subjects with more profound nocturnal desaturation, such as those with lower resting lung volumes [26, 27] or longer apnea duration [28], might demonstrate altered numbers of CECs and circulating EPCs. In addition, we chose to express the degree of hypoxemia as nadir $\mathrm{SaO}_{2}$, which may not be as sensitive as other noninvasive markers such as percentage of time during sleep spent with an $\mathrm{SaO}_{2}<90 \%$.

In the current study, we did not characterize the state of activation or viability of the CECs or EPCs, Recently, El Solh et al. [29] reported a significant increase in the number of CD146-positive and annexin V-positive cells in patients with OSA. The authors concluded that apoptotic CECs are increased in OSA. However, El Solh et al. acknowledge that they did not rigorously exclude patients with coronary artery disease. In our study, subjects were included only if they did not have vascular disease, risk factors for atherosclerosis, and other conditions reported to alter CECs.

Our results contrast with several papers suggesting an altered endothelial relaxation in patients with OSA, These global measures of endothelial function do show altered endothelium-dependent and -independent relaxation in patients with OSA, but do not speak to the mechanism. We did not observe substantial differences in the numbers of CECs, but it is likely that the cells remaining within the endothelium in OSA do not function normally.

In summary, this study did not reveal differences in circulating endothelial cells and circulating endothelial progenitor cells in subjects with OSA who did not have vascular disease or risk factors for cardiovascular disease. These results suggest that circulating endothelial cells and circulating endothelial progenitor cells are not markers of endothelial cell injury in patients with OSA without concomitant vascular disease. 


\section{Acknowledgments}

This article is the result of work supported by resources and the use of facilities at the Providence VA Medical Center and supported with a Lifespan Career Development Award to M. Stanchina; VA Merit Review and NIH HL 64936 grants to S. Rounds; and VA Merit Review and NIH HL67795 grants to E.O. Harrington. The authors thank Ms. J. Newton for technical support.

\section{References}

1. Peppard PE, Young T, Palta M, Skatrud J. Prospective study of the association between sleepdisordered breathing and hypertension. N Engl J Med. 2000; 342(19):1378-1384. [PubMed: 10805822]

2. Kaneko Y, Floras JS, Usui K, Plante J, Tkacova R, Kubo T, Ando S, Bradley TD. Cardiovascular effects of continuous positive airway pressure in patients with heart failure and obstructive sleep apnea. N Engl J Med. 2003; 348(13):1233-1241. [PubMed: 12660387]

3. Yaggi HK, Concato J, Kernan WN, Lichtman JH, Brass LM, Mohsenin V. Obstructive sleep apnea as a risk factor for stroke and death. N Engl J Med. 2005; 353(19):2034-2041. [PubMed: 16282178]

4. Marin JM, Carrizo SJ, Vicente E, Agusti AG. Long-term cardiovascular outcomes in men with obstructive sleep apnoea-hypopnoea with or without treatment with continuous positive airway pressure: an observational study. Lancet. 2005; 365:1046-1053. [PubMed: 15781100]

5. Kato M, Roberts-Thomson P, Phillips BG, Haynes WG, Winnicki M, Accurso V, Somers VK. Impairment of endothelium-dependent vasodilation of resistance vessels in patients with obstructive sleep apnea. Circulation. 2000; 102(21):2607-2610. [PubMed: 11085964]

6. Ip MSM, Tse HF, Lam B, Tsang KWT, Lam WK. Endothelial function in obstructive sleep apnea and response to treatment. Am J Respir Crit Care Med. 2004; 169(3):348-353. [PubMed: 14551167]

7. Solovey A, Lin Y, Browne P, Choong S, Wayner E, Hebbel RP. Circulating activated endothelial cells in sickle cell anemia. N Engl J Med. 1997; 337(22):1584-1590. [PubMed: 9371854]

8. Quilici J, Banzet N, Paule P, Meynard JB, Mutin M, Bonnet JL, Ambrosi P, Sampol J, DignatGeorge F. Circulating endothelial cell count as a diagnostic marker for non-ST-elevation acute coronary syndromes. Circulation. 2004; 110(12):1586-1591. [PubMed: 15364807]

9. Chong AY, Blann AD, Patel J, Freestone B, Hughes E, Lip GYH. Endothelial dysfunction and damage in congestive heart failure: relation of flow-mediated dilation to circulating endothelial cells, plasma indexes of endothelial damage, and brain natriuretic peptide. Circulation. 2004; 110(13):1794-1798. [PubMed: 15364797]

10. Bull TM, Golpon H, Hebbel RP, Solovey A, Cool CD, Tuder RM, Geraci MW, Voelkel NF. Circulating endothelial cells in pulmonary hypertension. Thromb Haemost. 2003; 90:698-703. [PubMed: 14515191]

11. Del Papa N, Colombo G, Fracchiolla N, Moronetti LM, Ingegnoli F, Maglione W, Comina DP, Vitali C, Fantini F, Cortelezzi A. Circulating endothelial cells as a marker of ongoing vascular disease in systemic sclerosis. Arthritis Rheum. 2004; 50:1296-1304. [PubMed: 15077314]

12. Asahara T, Kawamoto A. Endothelial progenitor cells for postnatal vasculogenesis. Am J Physiol. 2004; 287(3):C572-C579.

13. Schmidt-Lucke C, Rossig L, Fichtlscherer S, Vasa M, Britten M, Kämper U, Dimmeler S, Zeiher AM. Reduced number of circulating endothelial progenitor cells predicts future cardiovascular events: proof of concept for the clinical importance of endogenous vascular repair. Circulation. 2005; 111(22):2981-2987. [PubMed: 15927972]

14. Werner N, Nickenig G. Clinical and therapeutical implications of EPC biology in atherosclerosis. J Cell Mol Med. 2006; 10:318-332. [PubMed: 16796802]

15. Burnham EL, Taylor WR, Quyyumi AA, Rojas M, Brigham KL, Moss M. Increased circulating endothelial progenitor cells are associated with survival in acute lung injury. Am J Respir Crit Care Med. 2005; 172(7):854-860. [PubMed: 15976374]

16. Rechtschaffen, A.; Kales, A. A manual of standardized terminology, techniques and scoring system for sleep stages of human subjects. Rechtschaffen, A.; Kales, A., editors. Vol. vol. 204. Bethesda, MD: U.S. Department of Health, Education, and Welfare; 1968. 
17. American Academy of Sleep Medicine Task Force. Sleep-related breathing disorders in adults: recommendations for syndrome definition and measurement techniques in clinical research. Sleep. 1999; 22:667-689. [PubMed: 10450601]

18. Leung RST, Bradley TD. Sleep apnea and cardiovascular disease. Am J Respir Crit Care Med. 2001; 164(12):2147-2165. [PubMed: 11751180]

19. Rufii S. Circulating endothelial precursors: mystery, reality, and promise. J Clin Invest. 2000; 105(1):17-19. [PubMed: 10619857]

20. Barbe F, Mayoralas LR, Duran J, Masa JF, Maimó A, Montserrat JM, Monasterio C, Bosch M, Ladaria A, Rubio M, Rubio R, Medinas M, Hernandez L, Vidal S, Douglas NJ, Agusti AG. Treatment with continuous positive airway pressure is not effective in patients with sleep apnea but no daytime sleepiness. A randomized, controlled trial. Ann Intern Med. 2001; 134:1015-1023. [PubMed: 11388814]

21. Schafer H, Pauleit D, Sudhop T, Gouni-Berthold I, Ewig S, Berthold HK. Body fat distribution, serum leptin, and cardiovascular risk factors in men with obstructive sleep apnea. Chest. 2002; 122(3):829-839. [PubMed: 12226021]

22. Akashiba T, Minemura H, Yamamoto H, Kosaka N, Saito O, Horie T. Nasal continuous positive airway pressure changes blood pressure "non-dippers" to "dippers" in patients with obstructive sleep apnea. Sleep. 1999; 22:849-853. [PubMed: 10566903]

23. Maruo T, Nakatani S, Kanzaki H, Kakuchi H, Yamagishi M, Kitakaze M, Ohe T, Miyatake K. Circadian variation of endothelial function in idiopathic dilated cardiomyopathy. Am J Cardiol. 2006; 97:699-702. [PubMed: 16490441]

24. Hill JM, Zalos G, Halcox JPJ, Schenke WH, Waclawiw MA, Quyyumi AA, Finkel T. Circulating endothelial progenitor cells, vascular function, and cardiovascular risk. N Engl J Med. 2003; 348(7):593-600. [PubMed: 12584367]

25. Dyugovskaya L, Lavie P, Lavie L. Increased adhesion molecules expression and production of reactive oxygen species in leukocytes of sleep apnea patients. Am J Respir Crit Care Med. 2002; 165(7):934-939. [PubMed: 11934717]

26. Stanchina ML, Malhotra A, Fogel RB, Trinder J, Edwards JK, Schory K, White DP. The influence of lung volume on pharyngeal mechanics, collapsibility, and genioglossus muscle activation during sleep. Sleep. 2003; 26:851-856. [PubMed: 14655919]

27. Findley LJ, Ries AL, Tisi GM, Wagner PD. Hypoxemia during apnea in normal subjects: mechanisms and impact of lung volume. J Appl Physiol. 1983; 55(6):1777-1783. [PubMed: 6662768]

28. White DP. Pathogenesis of obstructive and central sleep apnea. Am J Respir Crit Care Med. 2005; 172(11):1363-1370. [PubMed: 16100008]

29. El Solh AA, Akinnusi ME, Baddoura FH, Mankowski CR. Endothelial cell apoptosis in obstructive sleep apnea. A link to endothelial dysfunction. Am J Respir Crit Care Med. 2007; 175:1186-1191. [PubMed: 17272785] 


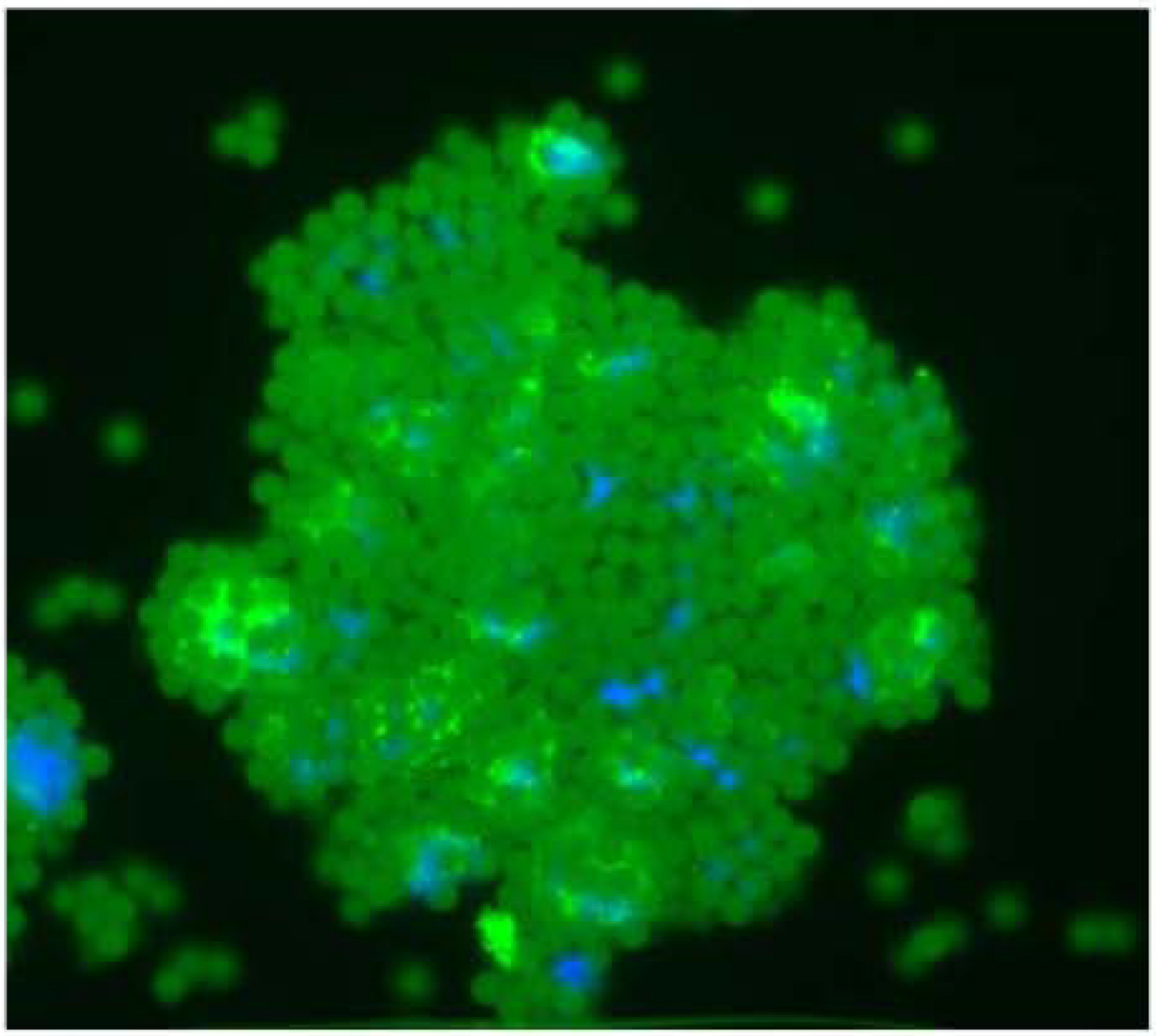

Fig. 1.

Identification of circulating endothelial cells using immuno-magnetic beads. Magnetic beads, precoated with pan-mouse IgG and bound to mouse a-CD146, were incubated with whole blood, isolated using magnetic concentrator, and suspended in Hoechst to label nuclei. The beads were viewed with UV epifluorescence (magnification 200x). The blue cells in the figure are the CECs using criteria described in Methods section 

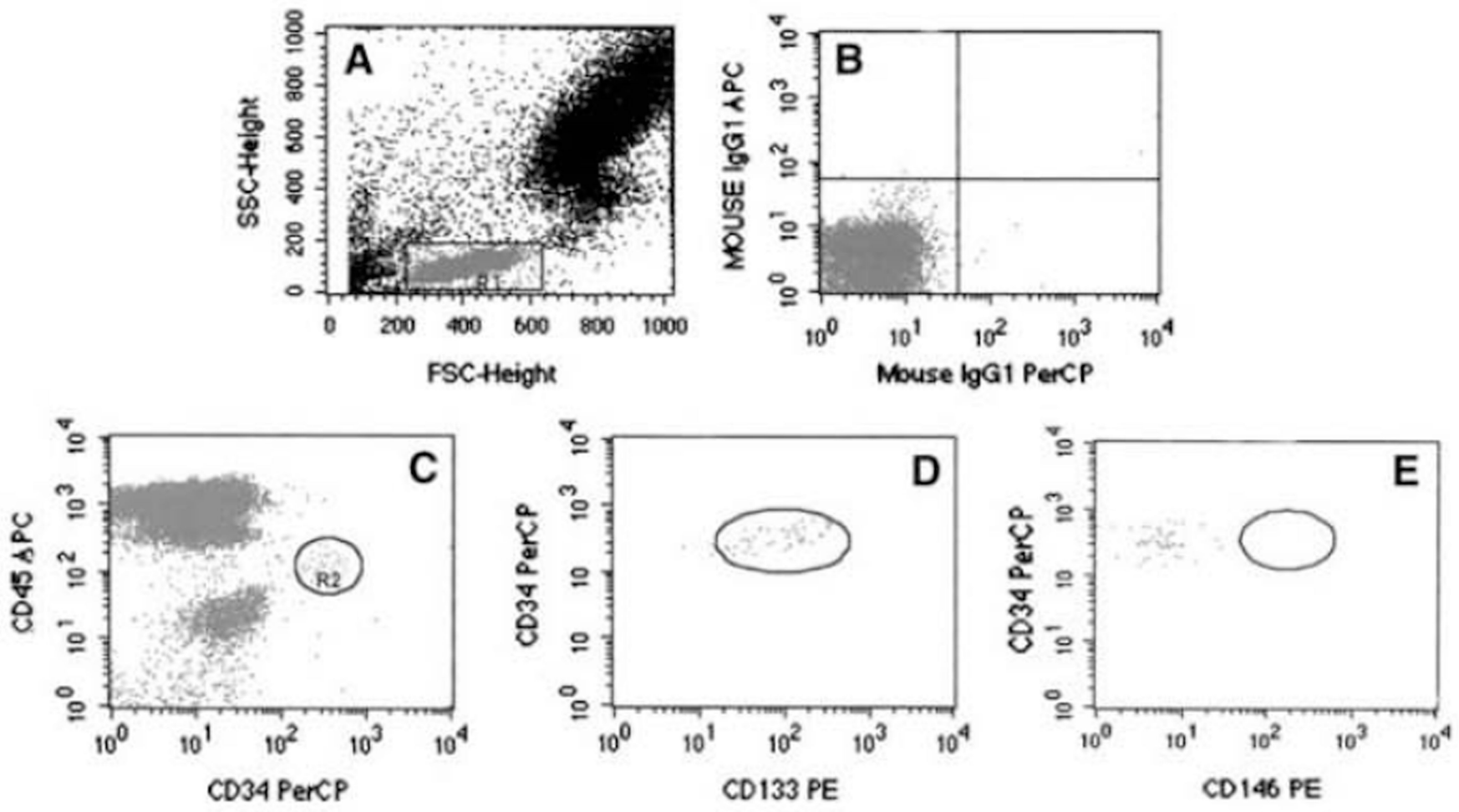

Fig. 2.

Fluorescence-activated cell-sorting (FACS) analysis for a subject. (A) $1 \%$ of events, plotting forward scatter (FSC) vs. side scatter (SSC). R1 selects all presumed cellular events. (B) Negative isotype controls. (C) A region of R1 that expresses CD34 highly and CD45 to a lesser degree. These cells are labeled R2. (D) Sequential analysis of cells from R2 in (C) showing cells staining positively for both CD34 and CD133. These cells are negative for CD146 (E). A representative FACS analysis is shown 

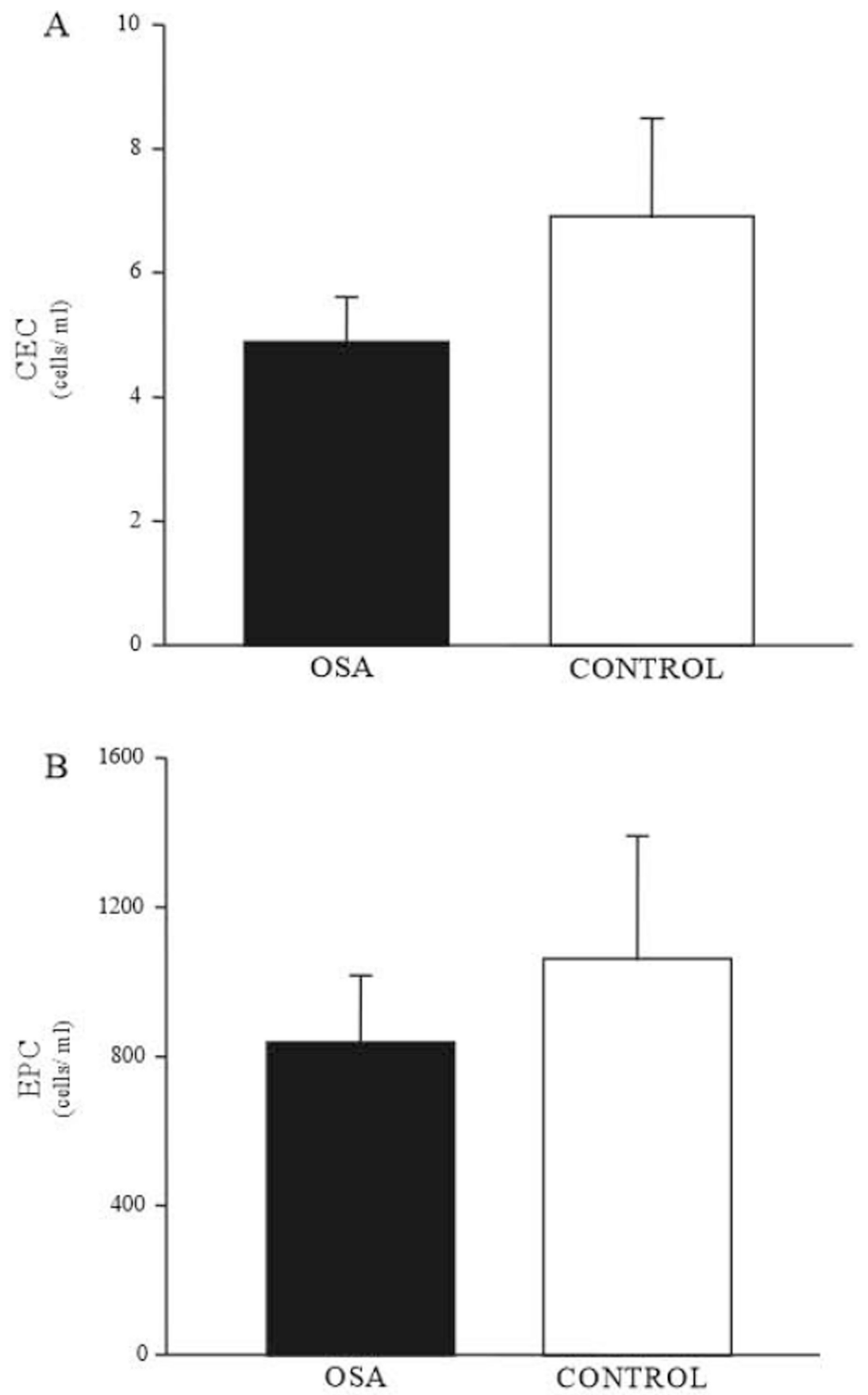

Fig. 3.

Circulating endothelial cells and circulating endothelial progenitor cells in subjects with OSA and controls. (A) CECs were purified by immunomagnetic bead separation and quantified by epifluorescence microscopy (OSA, $n=13$; control, $n=7, p=0.17$ ). (B) Circulating EPCs were quantitated by flow cytometry immunophenotyping (OSA, $n=17$; control, $n=10, p=0.51$ ) 


\section{Table 1}

Characteristics of study subjects

\begin{tabular}{lcr}
\hline & OSA (17) & Control (10) \\
\hline Age (years) & $47.1 \pm 1.8$ & $46.1 \pm 3.3$ \\
$\mathrm{BMI}\left(\mathrm{kg} / \mathrm{m}^{2}\right)$ & $28.7 \pm 1.1$ & $28.6 \pm 1.4$ \\
$\mathrm{AHI}($ events/h) & $24.8 \pm 2.8$ & $4.3 \pm 0.8^{*}$ \\
$\mathrm{SaO}_{2}$ Nadir (\%) & $85.4 \pm 1.2$ & $90.6 \pm 1.3^{*}$ \\
Epworth & $14.1 \pm 1.2$ & $8.3 \pm 1.6^{*}$ \\
\hline
\end{tabular}

Note: Data are presented as mean \pm SEM. Number of subjects is in parentheses. $\mathrm{BMI}=$ body mass index; $\mathrm{AHI}=$ apnea-hypopnea index; Epworth $=$ Epworth Sleepiness Scale score

* $p<0.05$ 